\title{
Proper priorities needed for the NPT
}

\section{Everybody's interest is that North Korea should not be aggressively pilloried for its less than full cooperation with the recent inspection of its nuclear plants; the survival of the Non-Proliferation Treaty is more important.}

IN just about a year, governments that are members of the Nuclear Non-Proliferation Treaty (NPT) should know the agenda of the conference later next summer to mark the twenty-fifth anniversary of the ratification of the NPT. It will be a crucial meeting. The text requires a positive decision by the existing members that the treaty should remain in force beyond next year. It is in everybody's interest that the decision should be to keep the treaty going.

As an instrument of international peace of mind, the NPT has been remarkably successful. The number of overt nuclear powers is no greater now than 25 years ago. And although there may be a number of covert nuclear powers (Israel, India and possibly Pakistan), others (Argentina and Brazil, for example) have disappeared from the lists. But more than that, the NPT has been one of several spurs towards the measures of strategic arms control the United States and the former Soviet Union have agreed; the latest development there is a remarkable agreement by which the two sides will actually count the plutonium triggers removed from each other's dismantled hydrogen-bomb warheads; that may be a basis for removing from a future version of the treaty the asymmetry by which nuclear powers are free to inspect each other while enforcing inspection on nonnuclear powers. It is to be hoped that next year's agenda will also include proposals on international custody of spent fuel and the like, but that is something else.

The danger is that the atmosphere for an agreement next year may be ruined by a row over North Korea, consistently (and almost mischievously) over the past two years a black sheep among NPT members, the example of Iraq notwithstanding. First, North Korea gave notice of its intention to withdraw from the NPT (of which it is a signatory), then it withdrew its withdrawal under diplomatic pressure, mostly from the United States, but appears to have forbidden a team of inspectors sent by the International Atomic Energy Agency to collect samples of plutonium from a radioactive glovebox at one nuclear site. The isotope composition of plutonium, which is easily determined, is well-known to be a test of whether the material has been bred to make bombs. The inference from North Korea's refusal is that its government has something to hide.

So there have been demands, notably in the United States, for economic sanctions against North Korea. The US Secretary of State, Mr Warren Christopher, has even given his view that China would probably not veto such a proposal, even if it failed to support it. Sadly, Christopher's frustrating experience in Beijing earlier last week is hardly such as to commend his opinion of what China will or will not do.

But in any case, given that next year's NPT conference must have it as a central objective to cement Chinese support for the NPT regime, even to risk a Chinese veto in the UN Security Council would dangerously divide the world's nuclear policemen (of which China must be one) on the eve of a conference where it is essential that they act in unison. That is a more important objective than North Korea's instant compliance with the inspection procedures. After all, despite talk of North Korean development in ballistic missiles as well as bomb technology, nobody seriously pretends that North Korea is now in a position to be a military threat to its neighbours - or that China would allow such uppishness. In due course, North Korea must be compelled to comply with the inspection regime it has invited, but too big a stick at this point could do more harm than good.

\section{Efficiency in research}

The Royal Society has fired a warning shot at the planned review of British research establishments.

ONCE upon a time, in the early decades of this century, the British government made several important innovations in the conduct of research, partly out of the recognition that it was technically ill-prepared for the First World War. A quarter of a century later, when the Second World War began, the tradition that it is an important function of government to carry out research was well-established. Many of the laboratories thus created, the radar establishment at Malvern (now part of the Defence Research Agency) performed superbly and won illustrious reputations. By the 1950 s, there was a tendency to create a new research establishment for each new problem or opportunity that arose. Since 1970, the tendency has been reversed; laboratories have been amalgamated or even closed. And now the government has embarked on what is called an "efficiency scrutiny" of 53 public laboratories supported by a variety of government departments (from agriculture to industry) but excluding defence.

The good news is that the newly created Office of Science and Technology (OST) is closely involved in the exercise. Whatever the detailed conclusions of the scrutiny, its general effect may be to give that office a continuing role in the 